\title{
As iniciativas de desenvolvimento em comunidades agroextrativistas na Amazônia
}

\section{Development initiatives in agroextractivists communities in the Amazon}

Alciene Oliveira Felizardo-Mestra em Agriculturas Familiares e Desenvolvimento Sustentável pela Universidade Federal do Pará (UFPA).E-mail: alcifelizardo@yahoo.com.br.

Carla Giovana Souza Rocha - Doutora em Desenvolvimento Rural pela Universidade Federal do Rio Grande do Sul (UFRGS). Professora da Faculdade de Etnodiversidade da Universidade Federal do Pará (UFPA). E-mail: crocha@ufpa.br.

\section{Resumo}

Este trabalho analisa o enfoque orientador de iniciativas de desenvolvimento e sua relação com o estilo de agricultura dos agroextrativistas na Amazônia, em particular nas ilhas de Abaetetuba, estado do Pará. Foram adotados recursos metodológicos de pesquisa qualitativa por meio da realização de entrevistas semiestruturadas e análise documental. Verificou-se que as iniciativas foram orientadas por uma matriz agroindustrial caracterizada por ações prédeterminadas, promoção de relações de dependência e incompatibilidade com as condições ambientais locais. Esse conjunto de características revela que as ações se pautaram em um enfoque programático marcado pela introdução de repertório técnico padronizado nos sistemas produtivos. Diante disso, as iniciativas de desenvolvimento limitaram a autonomia das famílias beneficiárias ao se distanciarem do enfoque estratégico que orienta o estilo de agricultura dos agroextrativistas.

\section{Palavras-chave}

Desenvolvimento. Autonomia. Matrizes Produtivas. Agroextrativistas.

\begin{abstract}
This work analyzes the guiding approach of development initiatives and their relationship with the style of agriculture of the agroextractivists in the Amazon, in particular in the islands of Abaetetuba-PA. Methodological resources of qualitative research were adopted through semistructured interviews and documentary analysis. It was verified that the initiatives were guided by an agroindustrial matrix, characterized by predetermined actions, promotion of dependency relations and incompatibility with the local environmental conditions. This set of characteristics reveals that the actions were based on a programmatic approach marked by the introduction of standardized technical repertoire in the productive systems. As a result, development initiatives have limited the autonomy of beneficiary families by distancing themselves from the strategic approach that guides the agriculturists' style of agriculture.
\end{abstract}

\section{Keywords}

Development. Autonomy. Productive Matrices. Agroextractivists. 


\section{INTRODUÇÃO}

O estudo de iniciativas de desenvolvimento no meio rural amazônico é desafiador, em função das especificidades ligadas ao meio biofísico e humano e das lógicas de reprodução presentes nos territórios dessa região. Os projetos de desenvolvimento, dependendo de seu nível de coerência com a realidade, estão sujeitos a diferentes trajetórias de fracasso ou êxito. Conforme Raynaut (1994), uma trajetória frequente é o fracasso desses projetos voltados para o meio rural, situação que ocorre principalmente quando são elaborados e implementados verticalmente. Nesse sentido, a coerência entre os projetos e os estilos de agricultura possui relação direta com os resultados das iniciativas de desenvolvimento.

Muitas intervenções realizadas por instituições privadas, órgãos públicos, Organizações Não Governamentais (ONG) etc. não têm considerado as estratégias produtivas que constituem os processos internos dos estabelecimentos familiares. Essas dinâmicas, quando mal compreendidas, implicam na "cegueira" dos agentes de intervenção (PLOEG, 2008). Assim, estes sugerem soluções únicas e padronizadas para os problemas no meio rural, desconsiderando as especificidades e diversidade que existem no seu interior (MORTIMORE, 2006).

Ao longo dos anos, muitos projetos de desenvolvimento agrícola têm sido desenvolvidos nas ilhas de Abaetetuba. Essas intervenções foram realizadas no contexto agroextrativista por diversas organizações, como a Universidade Federal do Pará (UFPA), o Instituto Federal de Educação, Ciência e Tecnologia do Pará (IFPA/Campus Castanhal), a Federação de Órgãos para Assistência Social e Educacional (Fase) e a Associação de Moradores das Ilhas de Abaetetuba (AMIA). Foram implantados projetos de plantio de cultivos perenes, criação de animais, fornecimento de instrumentos de pesca, entre outros. A maioria desses projetos foi direcionada à dimensão técnico-produtiva dos estabelecimentos, o que revela a necessidade de estudos para compreendê-los.

Diante disso, o objetivo deste trabalho é analisar o enfoque orientador dessas iniciativas de desenvolvimento e sua relação com o estilo de agricultura dos agroextrativistas na Amazônia, em particular nas ilhas de Abaetetuba (PA). Para atender a esta proposta, realiza-se, inicialmente, um debate acerca das diferentes matrizes que orientam os projetos de desenvolvimento no meio rural. Posteriormente, aborda-se o percurso metodológico escolhido, e, então, realizase um resgate das iniciativas de desenvolvimento que ocorreram nas ilhas de Abaetetuba, enfatizando umas dessas experiências para debater sua concepção orientadora e os desdobramentos de sua implantação. 


\section{AS MATRIZES PRODUTIVAS ORIENTADORAS DOS PROJETOS DE DESENVOLVIMENTO NO MEIO RURAL}

Os projetos voltados para processos de desenvolvimento técnicoprodutivo no meio rural são orientados por matrizes tecnológicas. Estas possuem princípios que orientam a tomada de decisão em relação ao formato tecnológico e a dinâmica de intervenção que será adotada. Para fins de análise dos projetos de desenvolvimento agrícola, é necessário compreender os diferentes princípios que orientam essas propostas de intervenção, os quais, de modo geral, distinguem-se entre as matrizes produtivas agroindustriais e endógenas.

A matriz produtiva agroindustrial está assentada na artificialização dos processos produtivos por meio da incorporação de fatores de produção externos, baseada em uma perspectiva de controle das condições de produção (SILVA, 2013). Para este mesmo autor, a estratégia principal dessa lógica se caracteriza pela maximização da produção física sem considerar as bases biofísicas que dão sustentação a ela. Ao estabelecer elevada dependência de fontes energéticas não renováveis, principalmente os combustíveis fósseis, o aumento produtivo acaba incrementando essa dependência, que se torna cada vez maior em função de novas exigências energéticas (MARTÍNEZ-ALIER, 1998). Para Silva (2013), tal realidade tem gerado a busca por novos modelos energéticos que solucionem essa crescente demanda e as implicações ambientais a ela associada.

A lógica produtiva endógena busca "otimizar as combinações ou o balanço entre a mão de obra disponível e a base de recursos autocontrolada para obtenção de níveis estáveis e crescentes de renda" (PETERSEN et al., 2017, p. 82). Diferente desta, a lógica agroindustrial prevê "incrementar a produtividade do trabalho para melhor remunerar/reproduzir o capital investido" (PETERSEN et al., 2017, p. 82). Desse modo, como mencionado pelo mesmo autor, o "ganho de intensidade" (enfoque camponês) e o "ganhos de escala" (matriz agroindustrial) expressam claramente a distinção entre os princípios orientadores dessas lógicas produtivas que norteiam os padrões de desenvolvimento dos sistemas família-estabelecimento.

Petersen (2011) distingue essas matrizes a partir de dois enfoques contrastantes, o estratégico e o programático. Enquanto o primeiro possui convergência com a matriz produtiva camponesa e corresponde às ações realizadas de acordo com as condições sociais e materiais do meio, o segundo associa-se à matriz produtiva agroindustrial e corresponde a ações pré-estabelecidas por padrões de desenvolvimento exógenos. Quando o processo de inovação é conduzido pelo enfoque estratégico, permite-se que as "famílias e suas comunidades exerçam sua inteligência criativa, espontaneidade e disposição aos riscos experimentais, com o 
objetivo de fazer frente à necessidade de tomar decisões no momento, em função de mudanças imprevistas no contexto" (PETERSEN, 2011, p. 157).

$\mathrm{Na}$ Amazônia, essas matrizes podem ser identificadas a partir das distintas trajetórias tecnológicas caracterizadas por Costa (2009). Este autor verificou que na região existem três trajetórias camponesas (lógica endógena): a T1, com sistemas convergentes para culturas permanentes e pecuária de leite; a T2, que envolve os sistemas agroflorestais, e a T3, que converge para pecuária de corte. Costa (2009) também identificou três trajetórias patronais (lógica agroindustrial): a T4, que abrange o conjunto de sistemas de produção que convergem para pecuária de corte; a T5, que envolve sistemas especializados de cultura perenes em forma de plantation, e a T6, que engloba os sistemas especializados de silvicultura.

O estudo sobre iniciativas de desenvolvimento e sua relação com as estratégias produtivas locais nas ilhas de Abaetetuba representa uma estratégia metodológica de projeção das descobertas para diversas áreas da Amazônia. Isso ocorre em função do mesmo estilo de agricultura presente nos estabelecimentos familiares dessas ilhas estar amplamente distribuído na região. Essa realidade foi identificada no estudo de Costa (2009), ao verificar a distribuição espacial dos estabelecimentos com as características de camponeses agroextrativistas (Trajetória-Tecnológica T2).

De acordo com Sá, Kanashiro e Lemos (2014), a abordagem das trajetórias tecnológicas vem oferecendo importante contribuição para a compreensão da realidade rural amazônica, por evidenciar sua diversidade a partir de um conjunto de aspectos e características. Nessa perspectiva, as descobertas dos estudos nas ilhas de Abaetetuba podem representar um caminho para a compreensão de iniciativas de desenvolvimento em contexto similares na região.

Existem disputas entre essas formas de desenvolvimento representadas pelas diferentes matrizes, principalmente a partir de sua relação com a natureza (OLIVEIRA, 2013), motivo pelo qual estas estabelecem complexas relações entre si. Isso pode ser observado no estudo de Costa (2009), ao mostrar que o crédito foi um impulsionador da transferência de recursos ecológico-produtivos de uma trajetória patronal (T4) para uma trajetória camponesa (T3), via incentivos governamentais. Nessa perspectiva, as relações entre as duas lógicas podem ocorrer em diferentes casos, entre os quais figuram os projetos de desenvolvimento agrícola. Tais projetos podem, entre outros fatores, promover iniciativas para um estilo de agricultura, a partir de princípios que não lhes são próprios.

As realidades amazônicas como as relativas às ilhas de Abaetetuba estão situadas analiticamente na trajetória T2 (sistemas agroflorestais), "que tem por base o extrativismo não-madeireiro em combinação com agricultura diversa, de 
culturas temporárias e permanentes" (COSTA, 2009, p. 38). Essa trajetória se enquadra nos princípios camponeses (endógenos) mencionados por Silva (2013). Segundo Petersen, Dal Soglio e Caporal (2009, p. 131), esses estilos de agricultura podem ser compreendidos como "modos de coerência material e simbólica de fluxos estrategicamente ordenados que relacionam as unidades produtivas com o contexto social, econômico e ideológico no qual estão imersos". Dessa forma, é necessário que as intervenções nesses espaços dialoguem com as particularidades de seu estilo de agricultura.

A disputa entre as matrizes agroindustrial e endógena também pode ser percebida por meio das distintas estratégias técnicas de gestão do agroecossistema. Para Petersen et al. (2017), a matriz agroindustrial está centrada na estratégia de redução das limitações ecológicas, diferente da matriz endógena (camponesa), que se baseia nas estratégias de convivência com o ecossistema. Ainda para esse autor, a estratégia de convivência está centrada na valorização de potenciais endógenos por intermédio da dinamização de processos ecológicos locais, de modo que estes possam interagir de forma positiva com os processos produtivos do agroecossistema. Para ele, trata-se de um equilíbrio entre as funções de produção econômica e reprodução ecológica. Por outro lado, a estratégia de redução das limitações ecológicas centraliza-se no controle, e busca, por meio da introdução de recursos exógenos (como fertilizantes, agrotóxicos, irrigação intensiva, entre outros), reduzir as decorrências de fatores ecológicos que afetam o desempenho dos sistemas de produção (PETERSEN et al., 2017). Portanto, essas matrizes produtivas que orientam os projetos de desenvolvimento também podem ser diferenciadas a partir das estratégias técnicas de gestão do agroecossistema. O estudo das relações entre esses enfoques, que orientam os diferentes estilos de agricultura, pode fornecer contribuições importantes para compreender as iniciativas de desenvolvimento voltadas para a Amazônia.

\section{METODOLOGIA}

A pesquisa foi realizada nas ilhas do Capim, Caripetuba e Xingu, todas situadas no município de Abaetetuba, localizado no território do Baixo Tocantins, a 62 km da cidade de Belém, capital do estado do Pará. O município de Abaetetuba possui 153.380 habitantes distribuídos nas áreas rurais (várzea ${ }^{1}$ e terra firme ${ }^{2}$ )

\footnotetext{
Várzeas são áreas inundadas periodicamente pelas marés, formadas por gleissolos (AZEVEDO, 2018).

2 A terra firme caracteriza-se pela altitude mais elevada do que a várzea, não sofre inundação por marés e, no caso das ilhas estudadas, constituem-se principalmente de latossolos (AZEVEDO, 2018).
} 
e urbanas (IBGE, 2017). São 72 ilhas compostas por rios, furos e igarapés e diferentes microbiomas, região constituída por 72 comunidades inseridas em 24 Projetos de Assentamento Agroextrativistas. Aproximadamente 51 mil habitantes vivem da agricultura, com destaque para as atividades de cultivo e/ou extrativismo do açaí, pesca, além da renda advinda do funcionalismo público e do comércio (AMIA, 2011). Todas as localidades estudadas possuem organizações sociais locais, as Associações de Projetos de Assentamento Agroextrativista (PAE).

Nas ilhas de Abaetetuba, a trajetória prevalecente é a camponesa T2 (COSTA, 2009), que se caracteriza internamente por sua diversidade social. Outro aspecto importante de ser mencionado é a questão da territorialização dessas populações. Esse processo, diferente das demais trajetórias camponesas (T1 e T3), ocorre em três microbiomas distintos: terra firme, várzea e água (CRUZ, 2007). $\mathrm{Na}$ terra firme, os agroextrativistas cultivam principalmente espécies perenes e semiperenes e extraem recursos florestais; na várzea, extraem recursos não madeireiros, e nas águas realizam a pesca. Nesses sistemas camponeses há forte presença do extrativismo associado a outras atividades, formas de reprodução social típicas das populações tradicionais amazônicas. Como afirmam Carvalho e Silva (2017, p. 97), o extrativismo é responsável por garantir a reprodução social das famílias, por meio tanto da comercialização quanto do consumo.

A pesquisa foi desenvolvida em outubro de 2016 e nos meses de maio, junho e novembro de 2017. Inicialmente foram entrevistadas quatro famílias agroextrativistas que participaram de projetos na ilha do Capim. Essas entrevistas permitiram a identificação de onze projetos realizados de 1996 a 2012 nas ilhas de Abaetetuba. A opção pela ilha do Capim se deu em função do conhecimento prévio por contato pessoal de uma das autoras. Partindo dessa imersão em campo, foi definido como recorte de pesquisa os projetos de criação de frango de granja implantados pela AMIA nas ilhas do município de Abaetetuba em função de quatro aspectos principais: I) recorrência: ter sido implementado mais de uma vez e em anos diferente; II) tempo: ter sido o mais recente; III) abrangência amostral: ter alcançado uma porção significativa de famílias nas ilhas de Abaetetuba, e IV) abrangência territorial: por ter sido implementado em outras ilhas do município, e não somente no Capim, onde se pretendia centrar.

Foram realizadas três entrevistas semiestruturadas e uma conversa informal com membros das gestões da Associação de Moradores da Ilha de Abaetetuba (AMIA) que participaram e/ou possuíam informações sobre as implantações de projetos nas ilhas. As entrevistas com membros das gestões foram conduzidas pelo princípio da arborescência (BEAUD; WEBER, 2014), em que o primeiro entrevistado indicou outra pessoa que pudesse repassar 
informações sobre os projetos desenvolvidos pela AMIA. Essas entrevistas permitiram acessar informações sobre a implantação dos projetos, o processo de construção destes desde a sua concepção, seus objetivos, a proposta técnica, os financiadores, entidades envolvidas, relações com os comunitários envolvidos quanto à participação, recursos, metodologia e avaliação. No Quadro 1 está apresentado o detalhamento dos procedimentos e a finalidade das entrevistas por etapa e tipo de entrevistado.

Quadro 1 - As entrevistas e conversas informais

\begin{tabular}{|l|l|l|l|}
\hline $\begin{array}{l}\text { Perfil do } \\
\text { entrevistado }\end{array}$ & Agroextrativistas & $\begin{array}{l}\text { Membros de } \\
\text { diferentes gestões da } \\
\text { AMIA (Secretário, } \\
\text { tesoureiro, } \\
\text { coordenador, etc.) }\end{array}$ & Agroextrativistas \\
\hline Localidade & Ilha do Capim & Abaetetuba (cidade) & $\begin{array}{l}\text { Ilha do Capim, } \\
\text { Caripetuba e Xingu }\end{array}$ \\
\hline Objetivo & $\begin{array}{l}\text { Identificar os projetos } \\
\text { implementados nas } \\
\text { ilhas de Abaetetuba }\end{array}$ & $\begin{array}{l}\text { Identificar os projetos } \\
\text { implementados nas } \\
\text { ilhas de Abaetetuba }\end{array}$ & $\begin{array}{l}\text { Aprofundamento } \\
\text { sobre o projeto e } \\
\text { práticas produtivas } \\
\text { locais }\end{array}$ \\
\hline $\begin{array}{l}\text { Período da } \\
\text { entrevista }\end{array}$ & $\begin{array}{l}\text { Outubro/2016 } \\
\text { Quantidade }\end{array}$ & $\begin{array}{l}\text { Maio e junho/2017 } \\
\text { 4ovembro/2017 }\end{array}$ \\
\hline $\begin{array}{l}\text { Projetos } \\
\text { que os } \\
\text { entrevistados } \\
\text { participaram }\end{array}$ & $\begin{array}{l}\text {-Materiais de pesca } \\
\text { (Rede de pesca, matapi) } \\
\text {-Criação de frango } \\
\text { de corte (Gallus gallus } \\
\text {-Viveiro de mudas } \\
\text {-Matapi }\end{array}$ & $\begin{array}{l}\text {-Criação de frango } \\
\text { de corte (Gallus gallus } \\
\text { domesticus) } \\
\text {-Materiais de pesca } \\
\text { (Rede de pesca, } \\
\text { matapi) } \\
\text {-Matapi }\end{array}$ & $\begin{array}{l}\text {-Criação de frango } \\
\text { de corte (Gallus } \\
\text { gallus domesticus) } \\
\text {-Matapi }\end{array}$ \\
\hline
\end{tabular}

Fonte: Elaborado pelas autoras (2017).

Para complementar essas informações, foi realizada a pesquisa documental, a partir da consulta de documentos como prestações de contas, proposta escrita do projeto submetido pela AMIA e a relação das localidades atendidas com os respectivos números de beneficiários. O tratamento das informações foi baseado na análise de conteúdo (CARDOSO et al., 2011) e associado à identificação das matrizes orientadoras dos projetos conforme os princípios mencionados por Silva (2013). Desse modo, as gravações das entrevistas foram transcritas com a utilização de um quadro sinóptico com categorias pré-estabelecidas, tais como: perspectiva de desenvolvimento, dimensão ecológica, dimensão técnica, 
dimensão econômica e dimensão social, conforme as sugestões de Petersen (2011). A análise de conteúdo simplificada foi fundamental para caracterizar os projetos de desenvolvimento agrícola, já que permitiu identificar as matrizes que orientaram seu desenvolvimento e implementação.

\section{RESULTADOS}

Para analisar os projetos de desenvolvimento implantados nas ilhas de Abaetetuba, realiza-se inicialmente um breve resgate histórico das iniciativas desenvolvidas nas ilhas do município. Em seguida, detalha-se com maior profundidade uma delas, o "Projeto Produzindo a Inclusão", promovido pela AMIA. O intuito é compreender sua concepção orientadora e suas implicações na realidade estudada.

\subsection{AS INICIATIVAS DE DESENVOLVIMENTO POR INTERMÉDIO DE PROJETOS NAS ILHAS DE ABAETETUBA}

A AMIA é uma organização de agroextrativistas que surgiu no ano de 1986, visando atender a população que reside no meio rural (rios, furos e igarapés) do município. Seu surgimento partiu da necessidade de acesso a políticas públicas, com o objetivo de proporcionar garantia de direitos e melhoria de vida dessas populações (AMIA, 2011), sendo um processo fortemente influenciado pela Igreja Católica por meio da Paróquia das Ilhas.

Um dos projetos mais mencionados no diálogo com os camponeses agroextrativistas foi o "Creche e Manutenção". Implementado de 1993 a 2002, ele foi um marco histórico da atuação da AMIA junto à Paróquia da igreja católica, em função da introdução da educação infantil nas ilhas de Abaetetuba.

Durante a implantação desse projeto surgiu a demanda de fornecer alimentação às crianças. Entretanto, as condições geográficas das localidades atendidas dificultavam o transporte dos alimentos, o que resultou na criação de frangos de corte (Gallus gallus domesticus) pelas famílias que possuíam filhos matriculados na educação infantil. Conforme o relato da entrevistada a seguir:

\footnotetext{
A proposta da criação do projeto surgiu da necessidade que a gente tinha. A gente comprava no Dohara ${ }^{3}$, frango congelado para levar para o interior a gente tinha que ter caixa e a gente não tinha nas ilhas de Abaetetuba energia elétrica, então não tinha freezer, não tinha geladeira, a gente tinha um gasto para vir buscar para armazenar e nesse percurso muito frango ficava podre (A. B., entrevista realizada durante a pesquisa de campo, em 2017).
}

3 Rede de supermercados localizada em Abaetetuba, Pará. 
Desse modo, embora voltado para a educação, esse projeto interviu nos sistemas produtivos dos agroextrativistas, já que propôs a inserção da criação de frangos de granja nos subsistemas de criação.

A partir dessa experiência, outros projetos de criação foram implementados nas ilhas de Abaetetuba. O mais recente foi o Projeto Produzindo a Inclusão ${ }^{4}$, que será analisado no próximo item. Em linhas gerais, ele atendeu 150 famílias por meio do fornecimento de matapis ${ }^{5}$, da criação de frangos e da criação de padarias comunitárias, e foi realizado em 24 comunidades de diferentes ilhas do município.

Os demais projetos identificados neste levantamento não foram expostos com maior nível de detalhamento no diálogo com as famílias, em função da dificuldade de resgate da memória dos processos vividos, causada por sua ocorrência remota. Dentre as iniciativas está o cultivo de banana, implementado pelo Programa Pobreza e Meio Ambiente na Amazônia (Poema) ${ }^{6}$ da Universidade Federal do Pará. Neves (2015) relata que o Poema foi idealizado em 1992 por pesquisadores da UFPA, com o apoio da Secretaria da Agricultura do Pará, da Daimler $\mathrm{AG}^{7}$ e do Fundo das Nações Unidas para a Infância (Unicef) ${ }^{8}$, visando integrar soluções ambientais com viabilidade econômica. Na Ilha do Capim, esse projeto incentivou a inserção da banana nos sistemas produtivos. Para isso, forneceram as mudas e orientações para sua implantação, porém, não houve acompanhamento regular e orientação técnica. De acordo com as famílias, o projeto não permaneceu nos sistemas produtivos dos agroextrativistas em função dessa falta de assistência.

Houve também a criação de peixe em tanques escavados, projeto desenvolvido pela Fase. Essa ação propôs a inserção de tambaqui (Colossoma macropomum) e tilápia (Pseudocrenilabrinae) nos sistemas de produção das famílias agroextrativistas. No que se refere aos instrumentos de pesca, trata-se de projetos que fornecem recursos materiais às famílias, por meio de fomento de atividades já existentes nos estabelecimentos. Os projetos de cultivo de hortaliças, viveiro de mudas, manejo de açaí e criação de peixes em tanque-rede desenvolvidos foram implantados pelo Núcleo de Estudos em Agroecologia (NEA) do Instituto Federal do Pará, Campus Castanhal, somente na Ilha do Capim. Essas

\footnotetext{
4 A Inclusão Produtiva é o "processo que conduz à formação de cidadãos, integrados ao mundo pelo trabalho. Tem como perspectiva proporcionar autonomia para vida digna sustentável" (BRASIL, 2010, p. 2), noção proposta pelo Ministério do Desenvolvimento Social e Combate a Fome por meio da Secretaria de Articulação para a Inclusão Produtiva.

5 Instrumento utilizado para capturar camarão (Macrobracbium nattereri). Possui formato cilíndrico e geralmente é produzido com materiais locais.

Cabe mencionar que não foi possível obter o ano exato em que ocorreu essa intervenção.

Multinacional alemã.

8 Do inglês United Nations Children's Fund (UNICEF).
} 
intervenções visaram a criação de Unidades Pedagógica de Experimentação Agroecológica (UPEA) de acordo com cada atividade proposta pelo projeto, demandadas em um diagnóstico prévio.

A criação de abelhas (Apis mellifera) também foi um projeto desenvolvido pelo IFPA (Campus Castanhal), que implementou UPEA originadas do levantamento de demandas realizado por alunos ${ }^{9}$ dessa mesma instituição. O projeto tinha por objetivo a diversificação produtiva de acordo com os princípios da agroecologia (AZEVEDO et al., 2011) e abrangeu a ilha Xingu e ilha do Capim. O Quadro 2 sintetiza algumas intervenções que ocorreram nas ilhas de Abaetetuba e que foram mencionadas no resgate histórico acima, a partir de datas aproximadas das implementações informadas pelas famílias entrevistadas.

Quadro 2 - Projetos implantados nas ilhas de Abaetetuba

\begin{tabular}{|c|c|c|c|}
\hline Projetos & Instituição promotora & $\begin{array}{c}\text { Ano imple- } \\
\text { mentado }\end{array}$ & Local \\
\hline Cultivo de banana & $\begin{array}{c}\text { Universidade Federal do } \\
\text { Pará (UFPA) }\end{array}$ & Sem dado & Outras ilhas \\
\hline $\begin{array}{l}\text { Criação de peixes em } \\
\text { tanques escavados }\end{array}$ & $\begin{array}{c}\text { Federação de Órgãos } \\
\text { para Assistência Social e } \\
\text { Educacional (Fase) }\end{array}$ & $\begin{array}{l}\text { Antes de } \\
1996\end{array}$ & Outras ilhas \\
\hline $\begin{array}{c}\text { Materiais de pesca (Rede } \\
\text { de pesca, matapi) }\end{array}$ & & 2005 & Outras ilhas \\
\hline Matapi & & 2006; 2012 & Outras ilhas \\
\hline $\begin{array}{c}\text { Criação de frango de corte } \\
\text { (Gallus gallus domesticus) }\end{array}$ & & $\begin{array}{c}1993 \text { a } 2002 ; \\
2006 ; 2012\end{array}$ & Outras ilhas \\
\hline Cultivo de Hortaliças & \multirow{5}{*}{$\begin{array}{l}\text { Instituto Federal do } \\
\text { Pará (IFPA-Campus } \\
\text { Castanhal) }\end{array}$} & 2012 & Ilha do Capim \\
\hline Viveiro de mudas & & 2012 & Ilha do Capim \\
\hline $\begin{array}{l}\text { Manejo de açaí } \\
\text { (Euterpe oleracea) }\end{array}$ & & 2012 & Ilha do Capim \\
\hline $\begin{array}{c}\text { Criação de abelhas } \\
\text { (Apis mellifera) }\end{array}$ & & 2010 & Outras ilhas \\
\hline $\begin{array}{l}\text { Criação de peixes em } \\
\text { tanque-rede }\end{array}$ & & 2012 & Ilha do Capim \\
\hline
\end{tabular}

Fonte: Elaborado pelas autoras (2017).

9 Alunos do curso técnico em agropecuária, integrado ao ensino médio com ênfase em agroecologia que é financiado pelo Programa Nacional de Educação na Reforma Agrária (Pronera). 
Dentre todos os projetos identificados é instigante a recorrência dos que envolvem a inserção de frango nos sistemas produtivos. Compreender essa iniciativa é estratégico devido ser representativo do enfoque adotado na maioria das intervenções que ocorreram nas ilhas de Abaetetuba. Diante disso, questionase: como esses projetos são concebidos e implementados nas localidades? Quais as concepções produtivas que orientaram seu desenvolvimento? Como a iniciativa de desenvolvimento se relaciona com o estilo de agricultura dos agroextrativistas?

\subsection{O "PROJETO PRODUZINDO A INCLUSÃO"}

O "Projeto Produzindo a Inclusão" (PPI), implantado pela Associação de Moradores das Ilhas de Abaetetuba, foi submetido em 2011 ao edital de Patrocínios do Banco da Amazônia S.A. (Basa) e executado no ano de 2012. Esse projeto envolveu 240 famílias distribuídas nos três subprojetos ${ }^{10}$ : matapi (150 famílias), padarias comunitárias (50 famílias) e criação de frango de corte (40 famílias). A AMIA acessou um recurso financeiro de $\mathrm{R} \$ 48.661$ (quarenta e oito mil seiscentos e sessenta e um reais) para aquisição dos materiais utilizados na implementação dos subprojetos, e cada família pôde acessar somente um deles. A seleção dos beneficiários foi realizada a partir do critério de vulnerabilidade social. Para contribuir nesta etapa, foram mobilizados os representantes das Comunidades Eclesiais de Base (CEB) das ilhas de Abaetetuba. Em função dessa relação entre a AMIA e a CEB, a maioria das famílias beneficiadas era católica.

Para a implementação das padarias, a AMIA forneceu diversos equipamentos e insumos (panela, moedor de carne, balança, cilindro, trigo, avental, touca, luva etc.). As famílias que optaram por esse subprojeto integraram-se em cinco grupos distintos, cada um composto por dez famílias. Cada grupo assumiu a responsabilidade de construir suas instalações (os espaços físicos para funcionamento das padarias) e participar das formações para dar início às atividades. Ao final do projeto, as famílias repassaram uma quantia ${ }^{11}$ do valor arrecadado à AMIA e o restante, sob autonomia da família, deveria ser destinado à continuidade da padaria.

Para o projeto de matapi, cada família recebeu 16 unidades deste equipamento e um saco de farelo. Essa iniciativa requereu das famílias principalmente o comprometimento em dar continuidade à ação. Ao final dela,

${ }_{10}$ Optou-se por denominá-los de subprojetos porque, embora sejam componentes do projeto "Produzindo a Inclusão", foram implementados de forma individual nas localidades e em momentos distintos, como se na prática fossem três projetos individuais.

11 Nas entrevistas não foi possível identificar o valor exato repassado pelas famílias beneficiárias à AMIA. Isso ocorreu porque os informantes (coordenadores da AMIA de diferentes gestões) não recordaram. 
os camponeses repassaram uma quantia do valor arrecadado à AMIA e o restante do recurso financeiro obtido, assim como no projeto de padarias, deveria ser destinado à continuidade da atividade.

Referente à criação de frango de corte, as famílias selecionadas assumiam a responsabilidade de construir os aviários de acordo com as informações repassadas nas oficinas de formação que orientavam o manejo das aves. Cada família recebeu 40 pintos de corte, $50 \mathrm{~kg}$ de ração inicial, $75 \mathrm{~kg}$ de ração de engorda, $50 \mathrm{~kg}$ de ração final, 1 bebedouro, 2 terramicinas e 2 vitaminas. Ao final dos 45 dias, as famílias deveriam comercializar todas as aves, repassar a AMIA aproximadamente $\mathrm{R} \$ 20,00$ (vinte reais) do valor arrecadado e utilizar o restante para dar continuidade à criação ${ }^{12}$.

O projeto "Projeto Produzindo a Inclusão" foi desenvolvido com o intuito de superar a vulnerabilidade das famílias agroextrativistas, conforme o relato de um dos entrevistados: "Era para contribuir com a questão da geração de emprego e renda para as famílias, aí nós tínhamos três focos, nós trabalhávamos com a questão do frango, a captura do camarão através do matapi e padarias comunitárias" (J. R., Abaetetuba, entrevista realizada durante a pesquisa de campo, em 2017).

Embora voltado para a questão social, a iniciativa proporcionou mudanças técnico-produtivas nos estabelecimentos por intermédio da criação de frango de granja. Isso revela uma característica dos projetos de desenvolvimento agrícola, que geralmente visam à inserção de uma atividade produtiva nos estabelecimentos familiares, como observou Dufumier (2007). De acordo com este mesmo autor, os projetos concebidos nesse formato pressupõem que as famílias possam acessar os meios de produção apropriados, com quantidades satisfatórias e em momentos cabíveis, o que justifica a necessidade de insumos e materiais externos, como ocorreu na iniciativa de desenvolvimento estudada.

Verificou-se que o projeto não promoveu a diversidade ecológica nos sistemas produtivos dos agroextrativistas. As famílias possuíam apenas a opção de escolha de um projeto e não havia autonomia para selecionar a raça de frango a ser criada, como afirma um dos entrevistados: "Nós trabalhávamos só com esses frangos normais de granja" (J. R., Abaetetuba, entrevista realizada durante a pesquisa de campo, em 2017). Desse modo, há um desajuste entre a restrição de opções de recursos ecológicos e a diversidade presente no estilo de agricultura das famílias.

Foi identificado também um aumento na dependência de recursos exógenos em função da exigência do uso de insumos em todas as fases da criação. Os insumos exigidos foram a vitamina, a maravalha e a ração balanceada.

12 Cabe mencionar que a partir do termino do projeto as famílias não recebiam mais o acompanhamento direto da AMIA. 
A distribuição da ração foi realizada em parcelas, conforme a etapa do projeto. Todos esses recursos eram exógenos aos estabelecimentos e exigiam controle de quantidade e tempo no fornecimento às aves. Como aponta o relato a seguir:

A ração foi dada por etapas, na entrega dos pintos nós forneciamos a ração inicial que foram uns $60 \mathrm{~kg}$, não lembro exatamente, e aí depois nós forneciamos a ração de engorda e quando ele já estava mais ou menos, nós fornecíamos a ração final. Quando estava acabando a ração, o pessoal vinha e a gente fornecia. Isso por uns 40 a 50 dias (J. R., Abaetetuba, entrevista realizada durante a pesquisa de campo, em 2017).

Esse relato demonstra que o projeto estabeleceu uma forte dependência em relação aos mercados. Trata-se de um fenômeno de externalização (PETERSEN, 2011), caracterizado pela mobilização de instrumentos e objetos por meio dos circuitos mercantis (PLOEG, 2008). Para Petersen (2011), quando esse fenômeno se amplia, a unidade inerente entre a produção e a reprodução é gradativamente dissolvida e alterada por uma rede complexa de novas relações comerciais e determinações técnicas e administrativas. Nessa perspectiva, ao incorporar recursos exógenos em seu formato, o projeto contribuiu para o processo de externalização das atividades econômicas dos agroextrativistas.

Verificou-se ainda que o projeto promoveu a disseminação de repertórios técnicos padronizados. A gestão técnica da atividade de criação era de responsabilidade das famílias beneficiárias. Entretanto, todas as atividades de manejo foram pré-estabelecidas em cursos de formação com orientações técnicas convencionais. Como afirma o entrevistado:

Foram dois cursos de formação. Um era de como cuidar, porque a criação de frango é meio melindroso [frágil], usando termo empirico, porque tem que ter técnica senão engripa [termo que refere-se a gripe do frango], então tem que ter todo um cuidado pra cuidar. Um ambiente não muito fechado, nem quente, a questão da vitamina essas coisas foram feitas e foi feito a questão de como trabalhar a questão do planejamento financeiro, de planejar de fazer o registro da produção, essas questões foram apontadas dentro do curso (J. R., Abaetetuba, entrevista realizada durante a pesquisa de campo, em 2017).

Esse depoimento revela a perspectiva de controle orientadora do manejo da criação. Dessa forma, percebe-se que tais orientações buscavam promover a redução de limitações ambientais, medida típica de lógicas produtivas agroindustriais.

O processo de decisão sobre o sistema de criação foi, em sua maioria, definido por agentes exógenos ao estabelecimento. Um dos membros da equipe técnica que executou o projeto afirmou que "Do frango, nós demos 40 pintos, a ração inicial, a ração de engorda, a ração final e a vitamina. E aí qual era a responsabilidade da família? Construir o espaço e cuidar" (J. R., Abaetetuba, entrevista realizada durante a pesquisa de campo, em 2017). Além disso, foram fornecidas orientações técnicas para a 
construção das instalações. O relato mostra que as famílias foram as responsáveis pela construção dos aviários, a partir de seus próprios recursos financeiros e sociais. Por outro lado, a decisão dos agroextrativistas era limitada, já que as instalações foram pré-definidas nos espaços formativos, o que mostra o estabelecimento de uma relação de dependência (MARTINEZ-ALIER, 1998) ligada à artificialização dos processos produtivos, um dos eventos fundamentais que caracterizam o modelo produtivista, como mencionado por Altieri (2002) e Silva (2013).

Ademais, o projeto não previa garantia de comercialização. A relação das famílias com o mercado era independente, pois a iniciativa não assegurava o escoamento da produção, conforme o relato a seguir: "No frango eles iam vender e iam administrar, a gente só queria que ele se organizasse para a sustentabilidade do projeto, mas a gestão mesmo da comercialização era dele" (J. R., Abaetetuba, entrevista realizada durante a pesquisa de campo, em 2017). Isso leva a refletir sobre dois desdobramentos. Se por um lado as famílias possuíam responsabilidade para a venda de sua produção, por outro não havia garantia de comercialização, o que as sujeitou à perda de recurso financeiro, já que a criação de frango de corte exigia venda total até aos 45 dias, término do ciclo produtivo.

O controle do custo da produção era condição de permanência das famílias no projeto, segundo o entrevistado:

Eles tinham que trazer a planilha pra gente dá uma olhada nos registros até pra gente quantificar depois quando chegasse na prestação de conta final, mostrar que o projeto teve resultado quantitativo e qualitativo, então a gente teve que faz̧er essa análise do material. E a questão do compromisso de levar a sério o projeto durante o período de execução (J. R., Abaetetuba, entrevista realizada durante a pesquisa de campo, em 2017, grifo nosso).

Desse modo, havia acompanhamento periódico às criações para cumprir as determinações previstas no projeto para a prestação de conta com o agente financiador, o Basa. Assim, havia pouca margem de indeterminação (PLOEG, 2008) dos agroextrativistas diante das recomendações estabelecidas, fato que impedia a organização independente do manejo realizado por eles em relação a atores externos.

A falta de autonomia das famílias é perceptível na forma como o projeto foi desenvolvido, desde sua concepção até a implantação: a iniciativa determinava as ações e as famílias eram responsáveis por executá-las. Ao analisar o projeto no seu conjunto, evidencia-se que seu formato tecnológico promoveu a dependência das famílias beneficiárias em relação a recursos exógenos e a repertórios técnicos padronizados. Para Dufumier (2007, p. 28), "projetos voltados para uma produção especializada não dão margem para que se resolvam os problemas de gestão eficiente dos recursos com os quais os agricultores se defrontam". 
O modelo orientador do projeto de criação de frango de granja foi confrontado pelas famílias ao realizarem as atividades de acordo com suas lógicas produtivas locais. Dessa forma, o modelo do projeto apresentou distanciamento do enfoque estratégico (PETERSEN, 2011), comumente adotado pelas famílias agroextrativistas, situação que pode ser percebida no quadro a seguir.

Quadro 3-O distanciamento entre o modelo do projeto e as atividades realizadas conforme o estilo de agricultura dos agroextrativistas

\begin{tabular}{|c|c|c|}
\hline $\begin{array}{l}\text { Fatores de } \\
\text { distinção }\end{array}$ & $\begin{array}{l}\text { Modelo orientado pelo projeto } \\
\text { Produzindo a Inclusão } \\
\text { (Lógica agroindustrial) }\end{array}$ & $\begin{array}{c}\text { Atividades realizadas pelos } \\
\text { agroextrativistas } \\
\text { (Lógica agroextrativista) }\end{array}$ \\
\hline Instalação & $\begin{array}{c}\text { Orientações para a construção } \\
\text { dos aviários a partir de recursos } \\
\text { exógenos }\end{array}$ & $\begin{array}{c}\text { "Pinteiros"13 produzido a partir } \\
\text { de recursos locais (madeira, palha, } \\
\text { barro, etc.) }\end{array}$ \\
\hline Tipo de ave & $\begin{array}{l}\text { Frango de raça única e } \\
\text { geneticamente modificada }\end{array}$ & $\begin{array}{c}\text { Frangos, patos, perus, etc., Sem } \\
\text { Raça Definida (SRD) }\end{array}$ \\
\hline Insumos & $\begin{array}{l}\text { Fornecimento de ração por fases } \\
\text { de desenvolvimento (inicial, } \\
\text { crescimento e engorda) }\end{array}$ & $\begin{array}{l}\text { Alimentação variada de acordo } \\
\text { com a adaptação das aves (ração, } \\
\text { milho quebrado, milho inteiro, } \\
\text { frutos in natura, etc.) }\end{array}$ \\
\hline $\begin{array}{l}\text { Modo de } \\
\text { condução }\end{array}$ & $\begin{array}{l}\text { Envolve as seguintes práticas: } \\
\text { - Fornecimento contínuo de ração } \\
\text { e água; } \\
\text {-Vitamina } \\
\text { - Bebedouros e comedouros; } \\
\text {-Limpeza dos equipamentos } \\
\text { regularmente; } \\
\text { - Pedilúvio (para entrada no } \\
\text { galinheiro); } \\
\text { - Iluminação (todas as noites) } \\
\text { - Cama de aviário de maravalha } \\
\text { (raspas de madeira que precisam } \\
\text { ser trocadas a cada } 15 \text { dias ou em } \\
\text { menor período se estiverem muito } \\
\text { úmidas); } \\
\text { - Lonas (para proteger do vento e } \\
\text { da chuva). }\end{array}$ & $\begin{array}{l}\text { Envolve as seguintes práticas: } \\
\text { - "Solta no terreiro"; } \\
\text { - "Deixa mariscar" (acessar } \\
\text { alimento de forma espontânea); } \\
\text { - Água com gotas de limão para } \\
\text { evitar doenças } \\
\text { - "Dá o que sobra e o que pega no } \\
\text { mato" (fornece alimentação } \\
\text { localmente disponível); } \\
\text { - "Prende a noite"; } \\
\text { - "Protege de bicho" } \\
\text { - "Tira do meio dos outros" (em caso } \\
\text { de doença); }\end{array}$ \\
\hline Finalidade & $\begin{array}{l}\text { Prioritariamente para venda para } \\
\text { complementação da renda }\end{array}$ & $\begin{array}{l}\text { Prioritariamente para consumo } \\
\text { com venda de excedentes ou de } \\
\text { acordo com a necessidade da } \\
\text { família }\end{array}$ \\
\hline
\end{tabular}

Fonte: Elaborado pelas autoras (2018).

13 "Pinteiros" é um termo local utilizado para designar instalações de aves, geralmente de frangos. 
Isso evidencia, assim como observado por Ploeg (2008), a centralidade das ações do projeto na produção física e obtenção de recursos financeiros. Diferente da realidade proposta pela iniciativa, as famílias agroextrativistas costumam realizar suas atividades a partir de uma lógica endógena que internaliza os recursos locais nas atividades de manejo.

Nessa perspectiva, o "Projeto Produzindo a Inclusão" possui diversas características da matriz produtiva agroindustrial (SILVA, 2013). Mesmo em situações em que apresentou tecnologias já utilizadas pelas famílias, como o matapi para captura de camarão, havia distanciamento entre suas orientações "empreendedoras" e a forma como os agroextrativistas gerenciam seus recursos financeiros. Isso ocorreu em função da exigência de guardar os rendimentos obtidos com a comercialização para reinvestimento na atividade, cuja proposta para sua manutenção divergiu das estratégias comumente adotadas pelas famílias. Essa divergência decorre da lógica de funcionamento dos sistemas produtivos, centrada no autoconsumo das famílias, em que a comercialização ocorre quando há excedente, pretensão específica de serviços ou aquisição de bens não produzidos no estabelecimento.

A descontinuidade das atividades produtivas foi a principal consequência das iniciativas de desenvolvimento. Isso decorreu do enfoque programático que orientou as ações nas localidades estudadas. Para os representantes da AMIA, entidade responsável pelo projeto, a experiência não foi exitosa em função da "falta de interesse" das famílias beneficiárias e de não possuírem "capacidade empreendedora". Tais concepções, presentes nas organizações sociais dos próprios agroextrativistas, como no caso da AMIA, implicam na elaboração de projetos que não condizem com as lógicas endógenas para a qual dedicam seu trabalho. Nesse sentido, os projetos de desenvolvimento são elaborados de forma distanciada do enfoque estratégico que orienta os sistemas de produção agroextrativistas.

\section{CONSIDERAÇÕES FINAIS}

O estudo mostrou que as iniciativas de desenvolvimento foram orientadas por uma matriz agroindustrial, caracterizada por ações pré-determinadas, promoção de relações de dependência e incompatibilidade com as condições ambientais locais. Este conjunto de características revela que as ações foram pautadas em um enfoque programático marcado pela introdução de repertório técnico padronizados nos sistemas produtivos. Diante disso, as iniciativas de desenvolvimento limitaram a autonomia das famílias beneficiárias ao se distanciarem do enfoque estratégico que orienta o estilo de agricultura dos agroextrativistas.

A partir dos resultados observados na pesquisa, conclui-se que é possível compreender outras realidades amazônicas imersas na trajetória T2, nas quais ocorrem implantações de projetos orientados pela lógica agroindustrial. 
Isso porque podem ocorrer os resultados potenciais identificados nas ilhas de Abaetetuba, tais como: a não continuidade das atividades inseridas nos sistemas produtivos; a perda de recursos investidos e o distanciamento entre os objetivos propostos pelo projeto e as lógicas produtivas agroextrativistas. Essas consequências revelam a necessidade de repensar as intervenções direcionadas à trajetória T2 (realidades agroextrativistas) na Amazônia, tendo em vista sua incompatibilidade com o enfoque programático, amplamente utilizado.

Nesse contexto, é necessário que as intervenções sejam orientadas pelo enfoque estratégico adotado pelos camponeses agroextrativistas. Os principais aspectos a nortearem as intervenções são a ampla participação, a flexibilidade (para alteração do projeto) e a priorização de recursos locais, seja para insumos ou para instalações, priorizando, assim, inovações construídas localmente, diversidade de animais com rusticidade (pato, peru, galinha caipira etc.), práticas contextualizadas de criação e a potencialização do uso de recursos locais. Portanto, as intervenções em realidades agroextrativistas amazônicas devem ser pensadas para os estabelecimentos de forma coerente com os repertórios culturais específicos de cada localidade, buscando internalizar e contextualizar as práticas e tecnologias.

\section{REFERÊNCIAS}

ALTIERI, M. Agroecologia: bases científicas para uma agricultura sustentável. Rio de Janeiro: AS-PTA, Ed. Agropecuária, 2002.

AMIA. Projeto Produzindo a Inclusão. Abaetetuba: AMIA, 2011.

AZEVEDO, H. P. Transição agroecológica: reflexões a partir de agroecossistemas de camponeses agroextrativistas na Amazônia numa perspectiva política. 2018. 172 f. Dissertação (Mestrado em Agriculturas Amazônicas) - Núcleo de Ciências Agrárias e Desenvolvimento Rural, Universidade Federal do Pará, Belém, 2018.

AZEVEDO, H. P. et al. Açaí com mel: uma experiência de pesquisa-desenvolvimento em comunidades ribeirinhas na Amazônia Paraense. Cadernos de Agroecologia, Recife, v. 6, n. 2, p. 1-4, 2011.

BEAUD, S.; WEBER, F. F. Guia para a pesquisa de campo: produzir e analisar dados etnográficos. Tradução: Sérgio Joaquim de Almeida. Revisão da tradução: Henrique Caetano Nardi. 2. ed. Petrópolis: Vozes, 2014.

BRASIL. Secretaria de Articulação para Inclusão Produtiva. Inclusão socioprodutiva. Brasília: Ministério do Desenvolvimento Social, 2010. 44 slides, color. Disponível em: https://www2.camara.leg.br/a-camara/estruturaadm/altosestudos/pdf/capacitacaomicro-empresas/mds. Acesso em: 04 out. 2018.

CARDOSO, A.; TEIXEIRA, E.; SPILKER, M.; SILVA, M.; OLIVEIRA, N. Análise de conteúdo de uma entrevista semiestruturada. Mpelearning, 2011. Disponível em: http://mpelearning.pbworks.com/f/MICO.pdf. Acesso em: 20 ago. 2017.

CARVALHO, J. P. L.; SILVA, L. M. S. Indicadores de sustentabilidade na compreensão de processo de adaptação de agroecossistemas familiares. Agricultura Familiar: Pesquisa, Formação e Desenvolvimento, Belém, v. 11, n. 1, p. 87-102, 2017. 
COSTA, F. de A. Desenvolvimento agrário sustentável na Amazônia: trajetórias tecnológicas, estrutura fundiária e institucionalidade. In: BECKER, B.; COSTA, F. A.; COSTA, W. M. (Orgs.). Desafios ao Projeto Amazônia. Brasília: CGEE, 2009. p. 215-363.

CRUZ, M. J. M. Territorialização camponesa na várzea da Amazônia. 2007. 274 f. Tese (Doutorado em Geografia Humana) - Departamento de Geografia, Faculdade de Filosofia, Letras e Ciências Humanas, Universidade de São Paulo, São Paulo, 2007. Disponível em: www.teses.usp.br/teses/disponiveis/.../TESE_MANUEL_JESUS_ MASULO_CRUZ.pdf. Acesso em: 17 nov. 2018.

DUFUMIER, M. Projetos de desenvolvimento agrícola: manual para especialistas. Tradução: Vitor Athayde Couto. Salvador: EDUFBA, 2007.

IBGE. Estimativas da população residente. Rio de Janeiro, 2017. Disponível em: http://cidades.ibge.gov.br/xtras/perfil.php?codmun=150010. Acesso em: 08 ago. 2017.

MARTÍNEZ-ALIER, J. Da economia ecológica ao ecologismo popular. Tradução: Armando de Melo Lisboa. Blumenau: Ed. da FURB, 1998.

MORTIMORE, M. Transição da agricultura no semi-árido africano. Revistas Agriculturas, v. 3, n. 3, p. 29-32, 2006.

NEVES, A. F. O projeto POEMA foi adiante? GGN “O Jornal de todos os Brasis”, 30 jan. 2015. Disponível em: http://jornalggn.com.br/fora-pauta/o-projeto-poema-foiadiante. Acesso em: 02 set. 2017.

OLIVEIRA, M. C. Diversidade da agricultura no Pará. In: GUERRA, G. A. D.; WAQUIL, P. D. (Orgs.). Desenvolvimento sustentável no Norte e no Sul do Brasil. Belém: Paka-Tatu, 2013. p. 87-113.

PETERSEN, P. Metamorfosis Agroecológica: un ensayo sobre Agroecologia Política. 2011. 286 f. Dissertação (Mestrado em Agroecologia) - Mestrado em Agroecologia com enfoque para a sustentabilidade rural, Universidade Internacional de Andaluzia, Sevilla, 2011. Disponível em: https://core.ac.uk/download/pdf/72022949.pdf. Acesso em: 17 nov. 2018.

PETERSEN, P.; DAL SOGLIO, F. K.; CAPORAL, F. R. A construção de uma Ciência a serviço do campesinato. Agricultura familiar camponesa na construção do futuro. Rio de Janeiro: AS-PTA, 2009.

PETERSEN, P; SILVEIRA, L. M da; FERNANDES, G. B; ALMEIDA, S. G de. Método de análise econômico-ecológica de Agroecossistemas. Articulação Nacional de Agroecologia (Brasil). Rio de Janeiro: AS-PTA, 2017.

PLOEG, J. D. Van der. Camponeses e impérios agroalimentares: lutas por autonomia e sustentabilidade na era da globalização. Tradução: Rita Pereira. Porto Alegre: UFRGS, 2008.

RAYNAUT, C. O desenvolvimento e as lógicas da mudança: a necessidade de uma abordagem holística. Desenvolvimento e Meio Ambiente, Curitiba, n. 1, p. 81-104, 1994.

SÁ, T. D. de A.; KANASHIRO, M.; LEMOS, W. de P. Interdisciplinaridade e transdisciplinaridade na pesquisa agrícola amazônica: um desafio para atingir a sustentabilidade. Revista Agroecossistemas, Belém, v. 6, n. 1, p. 110-124, 2014.

SILVA, L. M. S. O papel didático da crise da agricultura moderna para a compreensão da ascensão de um enfoque agroecológico. In: GUERRA, G. A. D.; WAQUIL, P. D. (Orgs.). Desenvolvimento rural no Norte e Sul do Brasil. Belém: Paka-Tatu, 2013. p. 227-248.

Texto submetido à Revista em 21.11.2018 Aceito para publicação em 04.07.2019 